\title{
O TERRORISMO TRANSNACIONAL E SUAS IMPLICAÇÕES NO CENÁRIO INTERNACIONAL
}

Patrícia Nogueira ${ }^{1}$

Esse artigo tem por objetivo fazer uma análise de um tema que se apresenta constantemente nas notícias dos jornais de todo o mundo: o terrorismo. Nesse artigo o termo terrorismo é tratado de uma forma geral, de modo a apresentar como se dá sua manifestação no cenário internacional, a partir das premissas da globalização e da maior interdependência entre os atores internacionais. É feita uma delimitação do que seria terrorismo, bem como das suas implicações, tais como a questão do seu financiamento, da sua transnacionalização, das suas possíveis causas, do novo terrorismo, do terrorismo de Estado $\mathrm{e}$, finalmente, do combate a esse flagelo, a fim de que se possa adquirir um conhecimento maior acerca da abrangência do referido tema, bem como facilitar a compreensão acerca da atuação dos grupos terroristas no cenário internacional hodierno.

Palavras-chave: Terrorismo Transnacional, Terrorismo de Estado, globalização, interdependência, novo terrorismo.

\section{1 - O TERRORISMO NO CENÁRIO INTERNACIONAL}

"Os atentados de 11 de setembro de 2001 contra as Torres Gêmeas de Nova York, o Pentágono e Washington D.C. colocaram na ordem do dia os problemas relativos à ambigüidade da noção de terrorismo."2 E, de fato, ainda não há um consenso acerca da definição

\footnotetext{
${ }^{1}$ Estudante de Relações Internacionais do Centro Universitário de Brasília UniCEUB.

${ }^{2}$ PELLET, Sarah. O Desafio da Comunidade Internacional frente ao Terrorismo: a ambigüidade da noção de terrorismo. In: Terrorismo e Direito: os impactos do terrorismo na Comuniade Internacional e no Brasil: as perpectivas políticojurídicas. Coordenador, Leonardo Nemer Caldeira Brant. $1^{\mathrm{a}}$ Edição Rio de Janeiro: Forense, 2003. p.9
}

Universitas - Relações Int., Brasília, v. 2, n.2, p. 221-244, jul./dez. 2004 
do termo nem mesmo na Organização das Nações Unidas, não havendo nenhuma Convenção Internacional definindo o termo. Considera-se difícil chegar a uma definição consensual acerca dessa concepção, uma vez que são envolvidos conceitos políticos, ideológicos, militares e religiosos.

Por anos, a Organização das Nações Unidas vem tentando definir quem seria terrorista e o que representa um ato de terror, controvérsias essas que têm postergado a adoção de uma nova convenção sobre terrorismo que incorporaria elementos-chave de instrumentos legais já existentes, permitindo que as nações busquem um tratado internacional que vise lutar contra o mesmo. No centro da disputa existe um campo politicamente minado, pois - muitas vezes quem, para uma nação, é terrorista, para outra é um lutador pela liberdade (freedom fighter). Segundo o advogado-chefe da ONU, Hans Corell, o problema é diferenciar entre terrorismo e o direito à autodeterminação e ao combate à ocupação estrangeira. ${ }^{3}$

O Princípio da Autodeterminação dos Povos é um dos mais importantes princípios do Direito Internacional Público. Essa premissa consiste em uma tendência das comunidades nacionais de, a partir de sua vontade, se organizarem na forma de um Estado, ou seja, o direito dos povos à livre determinação é um requisito essencial para o exercício de todos os direitos fundamentais em um contexto político na sociedade internacional. Contudo, apesar de terem uma base legal, os lutadores pela liberdade, que habitualmente são representados por uma minoria étnica, têm se valido de meios violentos em busca de atingir seus objetivos. Tal aspecto trouxe à tona o questionamento acerca da diferença entre esses lutadores pela liberdade e os denominados terroristas.

Para tornar claro que o presente trabalho se atém aos denominados terroristas, pode-se fazer a inferência de que os lutadores pela liberdade possuem fins políticos e altamente determinados, seja com objetivos separatistas, seja para adquirir maiores direitos dentro de determinado Estado. Normalmente, lutam contra um Estado soberano e não se atêm tanto a atingir a população civil. Já os

${ }^{3}$ Disponível em: 〈www.unodc.org/unodc/en/terrorism.html〉 . Acesso em: 22 de setembro de 2003.

Universitas - Relações Int., Brasília, v. 2, n.2, p. 221-244, jul./dez. 2004 
terroristas buscam seus objetivos políticos, religiosos, ideológicos ou outros por meio do ataque contra a população civil de forma a coagir um Estado ou mesmo toda a comunidade internacional.

A palavra terrorismo, como expressão política, surgiu com a Revolução Francesa, em seu período de maior violência. O terrorismo está presente na história da humanidade há muitos anos, contudo, nos últimos tempos, tem adquirido uma importância cada vez maior, fruto da maior dimensão que têm tomado os contrastes não só culturais e religiosos, mas as tensões políticas, tendo se intensificado devido ao processo de globalização. ${ }^{4} \mathrm{O}$ fato é que o terrorismo nunca deixou de permear as sociedades e, ainda que muitos fiquem pasmos com os ataques que ceifaram as vidas de muitos civis, ações como as acontecidas nos atentados ao World Trade Center e ao Pentágono, assistidas ao vivo por uma grande população, sempre fizeram parte ou mudaram rumos da história das sociedades. ${ }^{5}$

A gênese das organizações terroristas internacionais se deu no século XX a partir do desenvolvimento de diversos grupos fundamentalistas ${ }^{6}$, cujas ações repressivas à ordem vigente são inconcebíveis para a comunidade global. Atualmente essas organizações representam redes, algumas fundamentalistas, que se

\footnotetext{
${ }^{4}$ Globalização: Um mundo globalizado é caracterizado por acontecimentos políticos, econômicos, culturais, e sociais que se tornam cada vez mais interconectados, e também têm mais impacto. Em outras palavras, as sociedades são afetadas mais e mais extensamente, e mais profundamente por outras sociedades. (BAYLIS, John e SMITH, Steve. The Globalization of World politics. $2^{\text {nd }}$ Edition. New york: OXFORD, 2001. p. 7). Coloca em contato as mais diversas redes de interdependência, que interagem e proporcionam uma maior facilidade de movimentação de pessoas, recursos e informações através das fronteiras. Ou seja, corresponde a um redimensionamento e a um aumento das redes de interdependência em nível mundial.

${ }^{5}$ PELLET, Sarah. Op. cit. In: Terrorismo e Direito. Op. cit. p. 9-19

${ }^{6}$ Fundamentalismo: termo utilizado para definir toda e qualquer doutrina ou prática social que busca seguir determinados fundamentos tradicionais de forma extrema. Todo o fundamentalismo tende a tornar seus ideais absolutos, ou seja, reprimem e lutam contra doutrinas que vão contra suas premissas. Ideologicamente, os fundamentalistas reagem contra a modernidade, ou seja, vêem o que para eles é sagrado como a única forma legítima de ação. (Disponível em: 〈www.dhnet.org.br〉. Acesso em 11 de novembro de 2003.)
}

Universitas - Relações Int., Brasília, v. 2, n.2, p. 221-244, jul./dez. 2004 
apresentam de maneira descentralizada e não hierarquizada e que passaram a ter forte atuação no cenário internacional há alguns anos, agindo de forma ilimitada e atingindo o sistema internacional.

O processo de globalização vem se desenvolvendo em suas diversas dimensões, sejam políticas, econômicas, militares, ambientais ou sócio-culturais, a partir de toda a última década do Século XX. É importante frisar que, no contexto internacional formado anteriormente aos atentados de 11 de setembro, a lógica econômica possuía um grande predomínio na construção da ordem global. Contudo, após os atentados ao World Trade Center e ao Pentágono, e a partir de uma ordem global de maior interdependência ${ }^{7}$, pôde-se notar que as outras dimensões da globalização passaram a ter uma maior atenção na agenda internacional.

No cenário atual, ações antes isoladas e que interfeririam apenas em uma pequena e determinada região, hoje podem acabar gerando efeitos amplos devido ao intenso, crescente e dinâmico processo de globalização e o desenvolvimento da tecnologia da informação e dos meios de transporte, que impõem, cada vez mais, uma interdependência entre os Estados em todo o mundo. "Com globalização, o conseqüente redimensionamento do Estado e o acirramento da interdependência complexa entre os atores, os impactos diretos da ação terrorista ultrapassam as fronteiras dos Estados e atingem todo o sistema internacional". ${ }^{8}$

\footnotetext{
${ }^{7}$ Interdependência: significa que um Estado é afetado significativamente por forças externas, ou mais especificamente, significa, uma dependência mútua, ou seja, promove efeitos recíprocos entre países e entre outros atores em diferentes países. (Adaptação de: KEOHANE, Robert O.; NYE, Joseph S. Junior. Power and Interdependence. $3^{\text {rd }}$ Edition. London: Longman, 2001 p. 7.) A Interdependência se refere a situações nas quais atores ou acontecimentos em diferentes partes de um sistema se afetam mutuamente. (NYE, Joseph S. Junior. Compreender os Conflitos

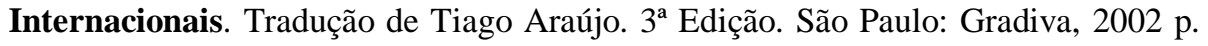
225) A interdependência envolve efeitos recíprocos entre Estados e entre atores em diferentes Estados. (Adaptação de: VIOTTI, Paul R.; KAUPPI, Mark V. International Relations Theory: Realism, Pluralism, Globalism and beyond. Third Edition Allyn \& Bacon, 1999. p. 215)

8 LASMAR, Jorge Mascarenhas. A ação terrorista Internacional e o Estado: Hegemonia e contra-hegemonia nas Relações Internacionais. In:Terrorismo e Direito. op. cit. p. 427
}

Universitas - Relações Int., Brasília, v. 2, n.2, p. 221-244, jul./dez. 2004 
Como bem expressam Viotti e Kauppi, a arena política mundial é dividida entre atores estatais e não-estatais. De acordo com as premissas da teoria realista, os principais atores, ou os mais importantes são os Estados, que são os atores dominantes, e cujos comportamentos são voltados para a promoção do equilíbrio de poder ${ }^{9}$. Para os pluralistas, além dos Estados, existem outros de grande relevância, como as organizações internacionais, as organizações nãogovernamentais, as empresas transnacionais e multinacionais, que se comportam de forma a reduzir os custos de suas operações, a promover maior acesso à informação e ao conhecimento, e a reduzir desconfianças entre si, em busca de gerar uma complementaridade de interesses. ${ }^{10}$

Estes outros atores, que surgem nas relações contemporâneas passam a ter acesso ao meio internacional, diversificando $\mathrm{e}$ aumentando o número de atores que agem na arena internacional. $\mathrm{O}$ fato é que atualmente, tanto um Estado, quanto uma corporação transnacional, um grupo terrorista, ou mesmo um indivíduo isoladamente, podem desencadear ações com repercussões locais ou em escala global, independentemente de suas origens e limitações.

Após os atentados de 11 de setembro, as ações terroristas têm sido uma preocupação relevante para a comunidade internacional embora desde pelo menos 1937 a Liga das Nações tenha elaborado uma Convenção para a Prevenção e Punição do Terrorismo. Posteriormente, sob os auspícios da Organização das Nações Unidas e as Organizações Regionais Intergovernamentais o terrorismo tem sido fator de discussão a partir de uma perspectiva legal e política. Desde 1963, a comunidade internacional tem elaborado alguns Instrumentos Legais Universais relativos à prevenção e à supressão desta ação ilegal.

\footnotetext{
9 Equilíbrio de poder: Ajuda a manter o sistema anárquico dos Estados independentes. Alguns realistas afirmam que a estabilidade ocorre quando existe uma proporção igual, mas outros defendem que a estabilidade ocorre quando um lado detém uma preponderância de poder, pelo que inibe o ataque dos outros. A busca dos realistas é de garantir a paz entre as nações. (NYE, Joseph S. Junior. Compreender os Conflitos Internacionais. Op. cit. p. 74-75)

${ }^{10}$ Adaptação de: VIOTTI, Paul; KAUPPI, Mark V. op. cit.
}

Universitas - Relações Int., Brasília, v. 2, n.2, p. 221-244, jul./dez. 2004 
Contudo, muitos Estados ainda não ratificaram esses instrumentos, ou não os estão implementando. ${ }^{11}$

\title{
1.2 - O TERRORISMO
}

Mesmo que tenha havido muitas tentativas, ainda não se chegou a um consenso sobre o que se pode caracterizar de ação terrorista. Uma das primeiras tentativas em se definir tais ataques terroristas ocorreu na então Liga das Nações, na primeira Convenção de Genebra de 1937, que previa em seu artigo 1": "Na presente Convenção, a expressão 'atos terroristas' quer dizer fatos criminosos dirigidos contra um Estado, e cujo objetivo ou natureza é de provocar o terror em pessoas determinadas, em grupos de pessoas, ou no público". ${ }^{12}$

Logo após, a Organização das Nações Unidas (ONU) também passou a lidar com o terrorismo de forma a tentar suprimi-lo ou mesmo extirpá-lo da Sociedade Internacional. Kofi Annan, atual Secretário Geral das Nações Unidas, qualifica o terrorismo como:

\begin{abstract}
"uma ameaça global com efeitos globais... sua conseqüência afeta cada aspecto da agenda das Nações Unidas - do desenvolvimento para a paz até os Direitos Humanos e a regra da Lei... Por sua natureza, o terrorismo é um assalto aos Princípios Fundamentais da Lei, ordem, direitos humanos, e o estabelecimento pacífico de disputas sobre as quais as Nações Unidas estão estabelecidas... As Nações Unidas têm um papel indispensável em promover uma estrutura legal e organizacional sem a qual a campanha internacional contra o terrorismo não pode prosseguir". ${ }^{13}$
\end{abstract}

O terrorismo, de uma forma geral, seria um ataque a um indivíduo específico ou a um grupo de indivíduos, de forma a assustar

${ }^{11}$ Disponível em: 〈www.unodc.org/unodc/en/terrorism.html>. Acesso em: 22 de setembro de 2003.

${ }_{12}^{12}$ PELLET, Sarah. op. cit. In:Terrorismo e Direito op. cit. p. 14

${ }^{13}$ Disponível em: 〈www.unodc.org/unodc/en/terrorism.html>. Acesso em: 23 de setembro de 2003.

Universitas - Relações Int., Brasília, v. 2, n.2, p. 221-244, jul./dez. 2004 
e coagir um grande número de outros, ou seja, é o recurso utilizado por uma minoria de maneira a impor à sociedade uma determinada convicção. ${ }^{14}$ Por ter uma definição tão ampla, o terrorismo é equiparado às guerrilhas. ${ }^{15}$ Mas, acima de tudo, um ato terrorista constitui um crime no sentido clássico e literal, tal como um assassinato ou um seqüestro, contudo, a partir de uma motivação política, religiosa ou étnica. ${ }^{16} \mathrm{E}$ ainda vale ressaltar que os terroristas internacionais atravessam as fronteiras para desferir ataques contra outros povos, ou mesmo dentro do próprio território nacional, procuram atingir alvos que representem outras nações, tais como as embaixadas do corpo diplomático. ${ }^{17}$

O termo terrorismo, de acordo com uma abordagem mais ampla, e de forma a abranger o maior número de ações, tanto de organizações clandestinas como de Estados, ou mesmo de pessoas isoladas, pressupõe o uso de meios coercitivos que se voltam contra o território de um Estado e a população civil, a fim de atingir seus objetivos, sejam políticos, religiosos, culturais, étnicos ou outros, por meio da dispersão de um clima de terror. Ou seja, como se entende

14 CLUTTERBUCK, Richard. Tradução de Virgínia Bombeta. Guerrilheiros e Terroristas Rio de Janeiro: Biblioteca do Exército Editora, 1977. p. 11

${ }^{15}$ Muitos analistas equiparam as guerrilhas aos terroristas modernos. A guerrilha é um tipo de combate caracterizado pelo choque entre formações irregulares de combatentes e os guerrilheiros possuem objetivos claramente definidos, os quais são mais políticos que militares. Defende-se que através das várias atividades dos guerrilheiros, figura também o terrorismo, que se desenvolve contra pessoas ou grupos diretamente ligados à classe que mantém o poder. (SUTTI, Paulo; RICARDO, Sílvia. As diversas Faces do Terrorismo. São Paulo: Editora HARBRA, 2003. p. 62). A Organização das Nações Unidas estabelece a diferença entre os guerrilheiros, que praticam o terrorismo político e os novos terroristas, que estão a cargo das redes e grupos terroristas internacionais: "Os primeiros, embora também usem métodos violentos, têm reivindicações mais claras e abrem a possibilidade de negociação política”. (NETO, Francisco Paulo de Melo. Marketing do Terror. Sao Paulo: Contexto, 2002. p. 29)

16 Adaptação de: LESSER, Ian O.; HOFFMAN, Bruce; ARQUILLA, John; RONFELDT, David; ZANINI, Michele. Countering the New Terrorism. Washington D.C.: RAND, 1999. p. v

17 Adaptação de: LESSER, Ian O.; HOFFMAN, Bruce; ARQUILLA, John; RONFELDT, David; ZANINI, Michele. Countering the New Terrorism. Washington D.C.: RAND, 1999. p. vi

Universitas - Relações Int., Brasília, v. 2, n.2, p. 221-244, jul./dez. 2004 
hoje, o terrorismo é considerado um instrumento de violência com a finalidade de atingir seus objetivos estratégicos. ${ }^{18}$ Destarte trata-se do uso de violência contra indivíduos, liberdades, propriedade, segurança comum, tranqüilidade e poderes públicos, com o propósito de pressionar um determinado governo ou sociedade para intimidar e persuadir as comunidades nacional e internacional.

Durante o período da Guerra Fria, os Estados Unidos e a União Soviética e a grande maioria dos países se preocupavam com a possibilidade de que um conflito regional pudesse levar a uma confrontação entre as superpotências que resultassem em consequiências drásticas para toda a comunidade internacional. Tal aspecto impôs uma certa restrição a determinadas ações, de forma que uma guerra armada realmente não chegou a ocorrer. Atualmente, notase que o mundo se apresenta mais instável que durante aquele período histórico, uma vez que não existe esta restrição, proporcionando o aparecimento de fenômenos tais como o terrorismo, o tráfico de drogas, o crime organizado, que representam novas ameaças à paz e à segurança internacionais.

\section{3 - O TERRORISMO DE ESTADO}

O termo terrorismo de Estado surgiu no século $\mathrm{XX}$ a fim de caracterizar governos ou regimes autoritários, totalitários em que os direitos de seus povos são constantemente violados, sendo, assim, uma ação ilegítima por parte de um Estado soberano. Ou seja, surgiu para representar o fascismo, o nazismo, os regimes latino-americanas de ditadura, que se deram entre o período dos anos 60 e 70. A condenação do terrorismo normalmente vem associada à condenação de outros crimes contra a humanidade, tais como o genocídio, o racismo, a dominação de povos e nações, impedindo a sua autodeterminação, gerando a miséria, aplicando a tortura, e impondo as diversas formas de exploração e de opressão da pessoa humana e dos seus direitos. ${ }^{19}$

A partir desse período, o termo denominado terror de Estado, difundiu-se por todo o mundo. Em nome de interesses dos dirigentes,

${ }^{18}$ SUTTI, Paulo e RICARDO, Silvia. Op. cit. p. 4

${ }^{19}$ SUTTI, Paulo; RICARDO, Silvia. Op. cit. p. 22-41

Universitas - Relações Int., Brasília, v. 2, n.2, p. 221-244, jul./dez. 2004 
houve o extermínio em massa de opositores, e até mesmo, de minorias étnicas. Os Estados também praticavam e pode-se dizer que praticam até hoje atos ditos terroristas. Exemplos seriam o do holocausto nazista, em que judeus foram perseguidos, baseando-se na pureza étnica preconizada por Hitler, e as Revoluções Comunista e Cultural na China, em que foi iniciada uma verdadeira eliminação de opositores do regime. ${ }^{20}$

Pode-se dizer que o Terrorismo de Estado, hoje, também é representado pela resposta do Estado-alvo das ações terroristas, ou seja, o uso da violência para reprimir determinado ataque sofrido. Algo a que se pode fazer alusão foram os ataques promovidos pelos Estados Unidos contra o Afeganistão como forma de retaliação pelos atentados ocorridos em 11 de setembro. Mesmo tendo sido legitimado pela $\mathrm{ONU}^{21}$, não é assim que um Estado deve proceder. Como exemplo pode-se citar o caso em que nos anos 80 , a Nicarágua foi vítima de um ataque conduzido pelos EUA e, ao invés de reagir militarmente, recorreu a todas as instâncias superiores, tais como a Corte Mundial, o Conselho de Segurança da ONU e a Assembléia Geral. Tais medidas deveriam ter sido tomadas pelos Estados Unidos com relação aos atentados às Torres Gêmeas do World Trade Center e ao Pentágono. ${ }^{22}$

Essencialmente, o termo discutido somente é utilizado para determinar atos violentos realizados contra os Estados Unidos e seus aliados. Mas, o ataque contra o Afeganistão que matou um enorme

\footnotetext{
${ }^{20}$ SUTTI, Paulo; RICARDO, Silvia.Op. cit. p. 22 - 41

${ }^{21}$ No dia 12 de Setembro de 2001, o Conselho de Segurança da Organização das Nações Unidas aprovou a resolução 1.368 condenando os ataques terroristas aos Estados Unidos e mostrou determinação no combate a ameaças à paz e segurança internacionais causada por terroristas. (Disponível em: 〈www.unodc.org/unodc/en/terrorism.html $>$. Acesso em: 28 de outubro de 2003) Tal resolução aponta os atentados de 11 de setembro como uma ameaça contra a paz e segurança internacional. (PELLET, Alain. Terrorismo e Guerra: O que fazer das Nações Unidas? In:Terrorismo e Direito op. cit. p. 174) A Resolução 1.368 reconheceu o Direito natural de legítima defesa individual ou coletiva, conforme previsto no art. 51 da Carta das Nações Unidas, autorizando e legitimando, assim, o ataque militar dos Estados Unidos contra o Afeganistão, em resposta aos atentados de 11 de setembro de 2001. (Ibidem.)

${ }^{22}$ CHOMSKY, Noam. 11 de setembro. Tradução de Luiz Antonio Aguiar. $4^{\mathrm{a}}$ ed. Rio de Janeiro: Bertrand Brasil, 2002. p. 26-29
}

Universitas - Relações Int., Brasília, v. 2, n.2, p. 221-244, jul./dez. 2004 
número de civis inocentes e fez diversas outras vítimas, uma matança a civis que já sofrem com a fome, pode ser definitivamente caracterizada como terrorismo, não uma luta contra tal violência.

O terrorismo de Estado pode ser reconhecido como o uso da violência de forma ilegal, ilegítima. Como afirma Chomsky, deve-se reconhecer que em grande parte do mundo os Estados Unidos são vistos como um Estado líder do terrorismo internacional. Um exemplo que este autor norte-americano apresenta é que em 1986 os EUA foram condenados pela Corte Mundial por "uso ilegal da força", ou seja, terrorismo internacional. ${ }^{23}$

Tal discussão acerca dessa concepção leva ao questionamento da legitimidade das ações de um Estado soberano. As teorias formadas no século XIX elaboraram categorias a que os Estados recorriam sempre que necessitassem legitimar uma declaração unilateral de guerra: a auto-assistência, a legítima defesa, a autoproteção, as necessidades sociais. ${ }^{24} \mathrm{E}$, ainda hoje, sob os auspícios da ONU, a Carta das Nações Unidas reconhece o direito inerente dos Estados à legítima defesa:

\begin{abstract}
“Art. 51. Nada na presente Carta prejudicará o direito inerente de legítima defesa individual ou coletiva, no caso de ocorrer ataque armado contra um membro das Nações Unidas, até que o Conselho de Segurança tenha tomado as medidas necessárias para a manutenção da paz e da segurança internacionais. As medidas tomadas pelos Membros no exercício desse direito de legítima defesa serão comunicadas imediatamente ao Conselho de Segurança e não deverão, de modo algum, atingir a autoridade e a responsabilidade que a presente Carta atribui ao Conselho para levar a efeito, em qualquer tempo, a ação que julgar necessária à manutenção ou ao restabelecimento da paz e da segurança internacionais."
\end{abstract}

${ }^{23}$ CHOMSKY, Noam. Op. Cit. p. 25

${ }^{24}$ SOARES, Guido Fernando Silva. Legitimidade de uma Guerra Preventiva, em pleno 2003? In: EUA e a Ordem Mundial: Uma nova Doutrina? Revista Política Externa. São Paulo. Vol. 12 n $^{\circ} 1$ Junho - Julho - Agosto 2003 p.10

Universitas - Relações Int., Brasília, v. 2, n.2, p. 221-244, jul./dez. 2004 
As normas jurídicas que constituem o arcabouço normativo da Organização das Nações Unidas são as únicas que, na atualidade, legitimam o emprego da força militar nas relações internacionais e tal aspecto se dá à delegação de poderes que os Estados fizeram à ONU. ${ }^{25}$ Portanto, somente sob as premissas do Direito Internacional e sob os auspícios da ONU é que um ataque militar contra outro Estado soberano pode se tornar legítimo.

$\mathrm{Na}$ luta contra o terrorismo não se pode atribuir aos Estados Unidos o papel central, uma vez que não têm autoridade moral nem política no cenário internacional, pois como país hegemônico, praticou diversos atos de covardia e terrorismo de Estado contra determinadas populações civis e países soberanos. Muitas ações norte-americanas são caracterizadas por irem contra as liberdades democráticas e os Direitos Humanos, contra as premissas do Direito Internacional. O terrorismo de Estado deve ser condenado em todos os seus aspectos e, até mesmo os atos praticados pelos Estados Unidos em escala mundial devem ser alvo da enérgica condenação por parte da sociedade internacional. $^{26}$

Os Estados Unidos podem ser considerados um país que é líder do terrorismo internacional, segundo Chomsky, por ter cometido diversas atrocidades consideradas ilegítimas e ilegais, tal como o acontecimento, nos anos 80, em que a Nicarágua foi vítima de um ataque militar conduzido pelos Estados Unidos, em que houve a morte de milhares de pessoas, incluindo nesta contagem, civis. Outro exemplo ainda mais arrasador que pode ser dado se trata da destruição das instalações farmacêuticas de AL-Shifa, no Sudão, em agosto de 1998, o que traz até os dias de hoje grandes consequiências para a população daquele país, tendo em vista que era a única instalação que produzia drogas contra a tuberculose a um preço acessível aos mais de 100 mil pacientes e, por causa de sua destruição, dezenas de milhares

\footnotetext{
${ }^{25}$ Idem. p. 7

${ }^{26}$ CARVAlHO, José Reinaldo; CARVAlHO, Lejeune Mato Grosso. Conflitos Internacionais num mundo globalizado. $2^{a}$ ed. São Paulo: Alfa Omega, 2003. p. 49
}

Universitas - Relações Int., Brasília, v. 2, n.2, p. 221-244, jul./dez. 2004 
de pessoas morreram em decorrência da destruição das instalações de Al-Shifa. ${ }^{27}$

Portanto, fica comprovada a ação dos Estados Unidos contra os preceitos do Direito Internacional, principalmente contra os Direitos Humanos. E, por este aspecto, vale ressaltar que este "foi o único país que já foi condenado por terrorismo internacional pela Corte Mundial e que vetou uma resolução do Conselho de Segurança que exigia que eles respeitassem as normas internacionais". ${ }^{28}$ Sendo assim, cumpre reafirmar a necessidade da cooperação internacional de forma que sejam coordenadas ações, sob a égide do Direito Internacional e da Organização das Nações Unidas, de modo a se restringirem ações de Estados que descumprem as normas internacionais já preestabelecidas.

\section{4 - O NOVO TERRORISMO}

Um outro entendimento trouxe à tona o termo Novo Terrorismo, que vem sendo utilizado por muitos teóricos a partir de meados dos anos 90, sendo o 11 de setembro visto como o marco desse, cuja organização, ações e objetivos são transnacionais, e não regionais como os do ETA (grupo separatista basco, caracterizado pela luta dos Bascos por sua autonomia política) ou do IRA (Exército Republicano Irlandês, que buscavam a autonomia da Irlanda em relação à Londres). Os novos terroristas têm táticas mais sofisticadas, inclusive suicidas. ${ }^{29}$ Ademais, o Novo Terrorismo não deve ser identificado com nenhuma nacionalidade, religião ou tradição cultural, assim como o eram anteriormente.

$\mathrm{Na}$ época do velho terrorismo, ou terrorismo tradicional, havia grupos conhecidos com propostas políticas bem determinadas e que, normalmente, assumiam seus atos. $\mathrm{E}$ os países que os patrocinavam não costumavam esconder o fato da comunidade global. Hoje, a situação é bastante diferente, tal como expressa o especialista norteamericano Ian $\mathrm{O}$. Lesser de que os ataques de 11 de setembro são

\footnotetext{
${ }^{27}$ CHOMSKY, Noam. Op. cit. p. 50-55

${ }^{28}$ Idem. P. 48-49

${ }^{29}$ O Império Vulnerável. Revista Veja. Editora Abril. Edição 1718. Ano 34 no 37 Edição Especial. 19 de setembro de 2001 p. 14
}

Universitas - Relações Int., Brasília, v. 2, n.2, p. 221-244, jul./dez. 2004 
exemplos típicos do novo terrorismo por apresentarem as seguintes características: enorme número de vítimas fatais, alvos simbólicos, ataques suicidas e demora em assumir a autoria. ${ }^{30}$

Grupos terroristas chamados de tradicionais apresentavam um certo limite às suas ações, de forma a expor as fraquezas de governos $\mathrm{e}$ grupos opositores e, não necessariamente buscavam causar danos maiores do que os que consideravam necessários para atingir seus objetivos, mas o novo terrorismo, busca conquistar suas metas através da publicação na mídia e não apresenta tantos limites quanto aos seus atentados, de forma que haja sempre uma repercussão, ainda que não seja necessário atingir o alvo determinado. ${ }^{31}$

O chamado terrorismo tradicional ou velho terrorismo era cometido por um grupo de indivíduos pertencentes a uma organização identificável que tinha um claro controle de seu aparato e objetivos econômicos, políticos ou sociais altamente definidos. ${ }^{32} \mathrm{O}$ fato é que no passado, o terrorismo se vinculava a grandes e organizados grupos, por vezes intrinsecamente ligados a Estados - normalmente não democráticos - já atualmente, as ações de maior vulto têm acontecido por parte de células de organizações que, com recursos tecnológicos, capacidade de planejamento, uma estrutura descentralizada, podem causar muitos e maiores estragos. ${ }^{33}$

O denominado novo terrorismo tem se intensificado, sendo opção política de grupos extremistas, e que sabem ter na mídia o principal meio de divulgação de suas idéias. Dessa forma, ações espetaculares tendem a ganhar mais espaço nos jornais e revistas ${ }^{34} \mathrm{e}$ na televisão, ao vivo, como apresentado nos atentados de 11 de setembro. Uma característica marcante a que se pode fazer alusão com relação ao chamado Novo Terrorismo seria a busca por publicidade, quer dizer que os terroristas buscam atingir seus objetivos por meio da mídia, pois produz resultados imediatos, tendo assim, uma grande

\footnotetext{
${ }^{30}$ O Império Vulnerável. Revista Veja. Editora Abril. Edição 1718. Ano 34 n 37 Edição Especial. 19 de setembro de 2001 p. 14

${ }^{31}$ Ibidem.

${ }^{32}$ Adaptação de: LESSER, Ian O. et. al. Op. cit. p. 8

${ }^{33}$ O Império Vulnerável. Revista Veja op. cit. 19 de setembro de 2001 p.11-15

${ }^{34}$ SUTTI, Paulo e RICARDO, Silvia. Op. cit. p. 113
}

Universitas - Relações Int., Brasília, v. 2, n.2, p. 221-244, jul./dez. 2004 
repercussão como nos ataques acontecidos às Torres Gêmeas, em que foi proporcionado à grande parte da população assistir o atentado à segunda Torre ao vivo, no exato momento em que ocorria.

\section{5 - CRIMES CORRELATOS E A QUESTÃO DO FINANCIAMENTO}

As organizações ditas terroristas - com uma ligação com a lavagem de dinheiro, comércio de drogas e especialistas em falsificação - apresentam mais do que uma semelhança meramente superficial com o crime organizado. ${ }^{35}$ Para financiar suas atividades, essas organizações se envolvem com outros tipos de atividades criminosas. ${ }^{36}$ Portanto, a luta contra estas ações deve também manter esforços no sentido de dificultar ou até mesmo desmantelar fontes de seus recursos.

No Simpósio intitulado "Combate ao Terrorismo: o papel das Nações Unidas", realizado entre 3 e 4 de junho de 2002, em Viena, discutiu-se a questão do financiamento, e sugeriu-se que os lucros obtidos com o tráfico de drogas fosse utilizado para manter tanto o repasse de armas, quanto as atividades terroristas. ${ }^{37}$ Portanto, existe a necessidade de se manter um estudo equilibrado de forma a combater tais ações partindo do princípio de que para combater crimes correlatos como a lavagem de dinheiro, o tráfico de drogas e o crime organizado, deve-se ter como objetivo de impedir que recursos obtidos ilicitamente circulem no mercado, uma vez que tais recursos, sendo lavados, podem facilmente ser utilizados para financiar a prática de outros atos ilícitos.

Assim sendo, e de forma a contextualizar um combate ao terror com base nas premissas da necessidade de uma cooperação internacional, devem ser implementados esforços no sentido de promover uma luta também contra os diversos crimes correlatos, de

\footnotetext{
${ }^{35}$ CARR, Caleb. A assustadora história do terrorismo. São Paulo: Ediouro, 2002. p. 19

${ }^{36}$ Disponível em: 〈www.interpol.int/Public/Terrorism/financing.asp〉. Acesso em: 23 de setembro de 2003.

${ }^{37}$ Disponível em: <www.unodc.org/unodc/en/terrorism.html>. Acesso em 23 de setembro de 2003.
}

Universitas - Relações Int., Brasília, v. 2, n.2, p. 221-244, jul./dez. 2004 
modo a dificultar suas ações. A cooperação internacional é algo essencial para que se combata a lavagem de dinheiro, o tráfico de drogas e, consequientemente, o terrorismo. Já existe um instrumento legal para um combate ao financiamento dessas ações sob os auspícios da ONU. Trata-se da Convenção das Nações Unidas para a Supressão do Financiamento do Terrorismo, de 1999, que contém disposições fundamentais para o combate à lavagem de dinheiro associada ao terror e prevê a importância da cooperação internacional, de uma ação coordenada em que os países utilizam-se de sua soberania, somando suas forças, em prol de uma finalidade comum. ${ }^{38}$

\section{6 - POSSÍVEIS CAUSAS}

Alguns autores apontam a globalização como um dos grandes motivos para que o 11 de Setembro tenha ocorrido. Segundo se defende, os terroristas atacaram a nação que, mais que qualquer outra, tanto impulsionou a globalização quanto se beneficiou dela. E é a este aspecto que é atribuída a escolha dos Estados Unidos como alvo, uma vez que um dos objetivos principais do terror é a de atacar a globalização em si. ${ }^{39}$ Contudo, a globalização pode ser vista talvez como uma correlação com o terrorismo, e não como uma causa deste flagelo.

Uma outra tentativa de explicação que tem sido dada aos atos de grupos islâmicos fundamentalistas seria, fazendo alusão a Samuel Huntington, o Choque das Civilizações, em que já se afirmava que:

“a política mundial está sendo reconfigurada seguindo linhas culturais e civilizacionais. Nesse mundo, os conflitos mais abrangentes, importantes e perigosos não se darão entre classes sociais, ricos e pobres, ou entre outros grupos definidos em termos econômicos, mas sim

38 Disponível em: <www.unodc.org/unodc/en/terrorism.html>. Acesso em: 23 de setembro de 2003.

${ }^{39}$ KENEDDY, Paul, et al. A Era do Terror. Organizadores: Strobe Talbott e Nayan Chanda. Tradução de Cristiana Serra. Rio de Janeiro: Editora CAMPUS, 2002. p. 12

Universitas - Relações Int., Brasília, v. 2, n.2, p. 221-244, jul./dez. 2004 
entre povos pertencentes a diferentes entidades culturais". 40

Contudo, o próprio Samuel Huntington manteve cautela em ratificar com os atentados de 11 de setembro sua tese do Choque de Civilizações, pois tanto os Estados Unidos como a Europa possuem uma forte presença mulçumana com relações econômicas privilegiadas. $^{4}$

É notável que algumas falhas tenham sido apresentadas na tese de "O Choque das Civilizações". Niall Ferguson, afirma que um dos perigos da tese de Huntington é que ela exagera a homogeneidade do Islã como religião mundial e do Ocidente. Chomsky afirma que a tese dos atentados ao World Trade Center e ao Pentágono tem pouco sentido ao serem apresentados como um possível choque de civilizações. Então ele defende, como exemplo, que o mais extremado Estado fundamentalista, depois do Talibã, é a Arábia Saudita, país com uma forte relação com os Estados Unidos. Um outro caso a que se pode fazer alusão seria o de os Estados Unidos e a Grã-Bretanha que, em 1980, prestaram forte apoio ao então aliado Saddam Hussein no período em que este cometia as maiores atrocidades contra os curdos, ou seja, contra a população civil, ${ }^{42}$ o que representa atos de terrorismo, segundo a definição apresentada neste trabalho.

Outro fator bastante relevante nessa questão são as ações de grupos religiosos fanáticos, ressaltando que não são apenas grupos islâmicos que os representam. Convém argumentar que a maioria dos mulçumanos repudia os ataques suicidas e os considera pecado extremo. O primeiro equívoco comum entre Ocidentais e Cristãos é considerar todo islâmico um extremista suicida e, por extensão, um terrorista em potencial. O que acontece é que muitas passagens do Corão (livro sagrado da religião islâmica), podem ser vistas de várias formas diferentes, de maneira a levar divergências entre os seguidores

${ }^{40}$ Huntington, Samuel P. O Choque de Civilizações. Tradução de M. H. C. Cortês. Rio de Janeiro: Objetiva, 1997. p. 21

${ }^{41}$ DUPAS, Gilberto. Fundamentos, contradições e conseqüências hegemônicas. In: Política Externa. São Paulo Vol. $11-\mathrm{n}^{\mathbf{0}} 3$ Dezembro - Janeiro - Fevereiro 2002/2003 p.7

${ }^{42}$ CHOSMKY, Noam. Op. Cit. p.35

Universitas - Relações Int., Brasília, v. 2, n.2, p. 221-244, jul./dez. 2004 
da religião. ${ }^{43} \mathrm{Na}$ verdade o que ocorre é que assim como a Bíblia, utilizada por cristãos, o Corão possui diversas formas diferentes de ser interpretado, sendo muitas vezes, considerado algo mais fundamentalista.

Os primeiros indícios apresentados aos ataques de 11 de setembro apontavam para terroristas fundamentalistas islâmicos, que nas últimas décadas realizaram vários atos contra os Estados Unidos, os quais se tornaram símbolo do ódio daqueles que consideram a civilização ocidental a responsável por todo o mal e desvirtuamento da ética e do comportamento. Além da política norte-americana próIsrael, sua política intervencionista internacional, seu poderio econômico que o torna um país hegemônico, suas posições e ações caracterizadas imperialistas, ajudaram a promover o sentimento antiamericanista. $^{44}$

Chomsky não crê que os terroristas tenham escolhido o World Trade Center como um alvo simbólico e que a globalização e a hegemonia cultural ajudam a gerar ódio contra a América, como muitos intelectuais do Ocidente costumam afirmar. Para o autor norteamericano, essas justificativas são muito convenientes tanto para os Estados Unidos, quanto para grande parte do Ocidente. Afirma também que os acontecimentos de 11 de setembro não têm nenhuma ligação com a globalização da economia. $O$ fato é que, o antiamericanismo possivelmente não decorre do ódio à modernidade ou da inveja ao avanço tecnológico, mas de uma história de intervenções de casos específicos. ${ }^{45}$

Noam Chomsky também entende que as causas para os ataques, especificamente os acontecidos em 11 de setembro, não podem ter sido a globalização, o imperialismo econômico ou os valores culturais, uma vez que, segundo ele, são assuntos absolutamente desconhecidos por Osama bin Laden e outros radicais islâmicos. Chomsky afirma veementemente que é mais reconfortante acreditar nas premissas dos comentaristas liberais, que asseguram que o ódio aos EUA ocorre por ser o país da vanguarda de uma "nova

${ }^{43}$ CARR, Caleb. Op. cit. p. 51

${ }^{44}$ SUTTI, Paulo e RICARDO, Silvia. Op. cit. p.106

${ }^{45}$ CHOMSKY, Noam. Op. Cit. p.34

Universitas - Relações Int., Brasília, v. 2, n.2, p. 221-244, jul./dez. 2004 
ordem mundial" que promove o capitalismo, o individualismo e a democracia, que deveriam imperar em todo o mundo. ${ }^{46}$

"O terrorismo emerge como uma grande reação, um obstáculo no caminho da modernidade capitalista discriminatória, exploratória e excludente por princípio e natureza". ${ }^{47}$ E seus principais alvos são a modernidade capitalista e, conseqüentemente, os Estados Unidos, representam o país hegemônico dessa nova ordem. A partir desse debate, pode-se inferir que as ações terroristas podem ser entendidas como um movimento de contra-hegemonia ${ }^{48}$ na medida em que é vista como um movimento de recusa e oposição de valores difundidos por um grupo hegemônico. ${ }^{49}$ Trata-se, portanto, do uso da força para manifestar sua contrariedade a determinados valores que muitas vezes são impostos como sendo valores universais.

Tais questionamentos geram controvérsias, tal como expressou o norte-americano Walter Laqueur, um dos mais respeitados estudiosos do fenômeno do terrorismo: "o terrorismo se nutre das justificativas que tiram dos ombros de seus autores o peso moral do crime que cometem". Laqueur sustenta que todos esses atos devem merecer condenação independentemente da motivação que os terroristas obtiveram. Não existe, portanto, um objetivo lógico em procurar justificativa para os atos de terror. ${ }^{50}$ Este aspecto imputa também a atos de Estados soberanos que podem ser denominados terroristas. Pois, como cumpre ressaltar, há formas apropriadas, legais

${ }^{46}$ Idem. p. 139

${ }^{47}$ NETO, Francisco Paulo de Melo. Op. cit. p. 34

${ }^{48}$ Hegemonia - "Segundo Gramsci, numa sociedade de classes, a supremacia de uma delas se exerce sempre através das modalidades complementares e, de fato, integradas, se bem que analiticamente dissociáveis, do domínio e da Hegemonia". A hegemonia atua como princípio de unificação dos grupos dominantes e, ao mesmo tempo como disfarce do domínio de classe. (BOBBIO, Norberto; MATTEUCCI, Nicola; PASQUINO, Gianfranco. Dicionário de Política. Tradução de Carmen C. Varriale, Gaetano Lo Mônaco, João Ferreira, Luís Guerreiro Pinto Cacais e Renzo Diniz. $11^{\text {a }}$ ed. Brasília: Editora Universidade de Brasília, 1998. p. 580 - 581)

49 LASMAR, Jorge Mascarenhas. A ação Terrorista Internacional e o Estado: Hegemonia e contra-hegemonia nas Relações Internacionais. In: Terrorismo e Direito op. cit. p. 441

${ }^{50}$ Terror sem Limites. Revista Veja. Editora Abril - Edição 1817. Ano 36 n 34. 27 de agosto de 2003. p. 47

Universitas - Relações Int., Brasília, v. 2, n.2, p. 221-244, jul./dez. 2004 
e legítimas de se proceder em relação a crimes, sejam quais forem suas proporções, tal como foi apresentada anteriormente a importância de manifestar controvérsias frente autoridades supranacionais, tais como a ONU.

\section{7 - TECNOLOGIA DA INFORMAÇÃO E A DISSEMINAÇÃO DAS REDES TERRORISTAS}

O tratamento do fenômeno do terror pode ser comparável àquele dispensado ao crime, ou seja, pode-se reduzir o índice de assaltos e assassinatos, mas não acabar de vez com eles. Podem ser minimizados os efeitos destas ações, mas não se pode afirmar um combate definitivo. O combate necessário a essas redes será feito, não simplesmente pela captura de Osama bin Laden, ou pelo ataque militar ao Afeganistão, mas por outros meios, tais como o rastreamento financeiro, o combate aos paraísos de lavagem de dinheiro, os amplos compromissos de acordos internacionais para coordenação de ações, o reforço das políticas nacionais acerca das medidas de segurança e a melhoria de iniciativas de inteligência.

Pelos motivos propostos anteriormente, tais como a globalização e a maior interdependência, a guerra contra o terrorismo não se dá contra um indivíduo, um grupo, uma religião ou um país. Ao contrário, o adversário é uma rede global de organizações. Uma destas organizações que estão mais em evidência nos dias de hoje, a Al Qaeda (A Base), é um exemplo nítido de que não possui estrutura vertical, hierarquizada. A referida organização é formada por células relativamente independentes, responsáveis pela elaboração e execução de atos de terrorismo. Desta forma, torna-se muito mais complexo identificar seus membros porque na maioria das vezes ocorre que uma ação determinada por uma célula que nem chega ao conhecimento de outras células da mesma organização. ${ }^{51}$

Como afirma Chomsky, o envolvimento da rede do saudita bin Laden, a Al Qaeda, nos atentados ocorridos em 11 de setembro é bastante plausível. Contudo, por ser composta por estruturas

${ }^{51}$ SUTTI, Paulo e RICARDO, Silvia. Op. cit. P.108

Universitas - Relações Int., Brasília, v. 2, n.2, p. 221-244, jul./dez. 2004 
descentralizadas e não hierarquizadas, e que, segundo ele, possuem elos de comunicação interna muito limitados. É bastante plausível crer que bin Laden esteja dizendo a verdade quando afirmou não ter conhecimento da operação que destruiu os símbolos do poder econômico norte-americano. ${ }^{52}$

As organizações terroristas de alguns anos atrás possuíam células que podiam facilmente sofrer infiltração e serem denunciadas sem a dificuldade que as agências internacionais responsáveis pelo cumprimento da lei e os serviços de inteligência experimentam hoje, quando perseguem os terroristas modernos. Tendo em vista que os denominados novos terroristas têm demonstrado um sólido conhecimento operacional dos níveis da comunicação e da tecnologia da informação, possivelmente, têm se utilizado de facilitadores tecnológicos que são proporcionados cotidianamente e que vem se tornando cada vez mais acessíveis, como a Internet e os telefones celulares. $^{53}$

Os novos terroristas são caracterizados por serem de difícil controle, vez que se torna quase que impraticável aplicar uma punição a um inimigo tão globalizado, disposto em redes transnacionais, sem interdependência entre as células que as compõem, cuja organização é feita de maneira descentralizada e não hierarquizada. Tal ocorre, possivelmente, porque um amplo acesso às tecnologias de destruição permite seu uso por células dispersas da rede, pois os avanços da tecnologia e da globalização ampliam o alcance dos atos do terrorismo ao facilitarem a movimentação, as redes e a conspiração dos terroristas, com ou sem o apoio de Estados. ${ }^{54}$

\section{8 - O COMBATE}

Alguns teóricos defendem que o combate ao terrorismo, para ser eficiente, tem que ser realizado a partir de ações militares. Caleb Carr afirma que, hoje, existe a necessidade de uma ação militar

${ }^{52}$ CHOMSKY, Noam. Op. Cit. p. 68

${ }^{53}$ BRIGAGÃO, Clóvis. O 11 de setembro: Novas ameaças à paz. In: Terrorismo e Direito. Op. cit. p. 347-355

${ }^{54}$ NETO, Francisco Paulo de Melo. Op. cit. p. 37-38

Universitas - Relações Int., Brasília, v. 2, n.2, p. 221-244, jul./dez. 2004 
constante e que esta atitude é a única opção para se combater o terrorismo. Segundo este escritor norte-americano:

"A resposta bem-sucedida à ameaça terrorista, portanto,
não está em repetidas análises dos movimentos
terroristas contemporâneos tomados individualmente,
nem em tentativas legalistas de condenar seu
comportamento em tribunais internacionais, nem em
políticas e medidas reacionárias que punem as
populações civis tanto quanto os terroristas que operam
em seu meio. Em vez disso, está na formulação de uma
estratégia abrangente e progressiva que possa tratar todas
as ameaças terroristas com as únicas medidas coercitivas
capazes de afetar ou moderar o comportamento
terrorista: ofensivas militares preventivas destinadas a
fazer com que não só terroristas, mas também Estados
que abrigam, provêem e de alguma forma ajudam esses
indivíduos, experimentem a mesma insegurança
constante e que tentam impor a suas vítimas.

Contudo, esse pensamento vai contra as premissas básicas dos Direitos Humanos e do Direito Internacional. A partir dessa argumentação, é importante se ater ao aspecto do unilateralismo por parte da política norte-americana. Em um primeiro momento, após os atentados de 11 de setembro, houve um sentimento de solidariedade por parte de toda a comunidade internacional e uma intenção em apoiar os Estados Unidos em sua empreitada contra o terrorismo. Contudo, em um segundo momento, notou-se que alguns países passaram a apresentar certas ressalvas, permitindo assim a percepção clara na política de Bush de que o Governo norte-americano não hesitará em agir sozinho e nem em utilizar a força contra os denominados terroristas, os países que possivelmente os abrigam e, conseqüentemente, contra civis.

A visão mais aceita e, certamente, a mais coerente com a premissa da necessidade do respeito aos Direitos Humanos no cenário internacional é a expressa pela ONU. Na Assembléia Geral das Nações

${ }^{55}$ CARR, Caleb. A assustadora história do terrorismo. São Paulo: Ediouro, 2002. p. 25

Universitas - Relações Int., Brasília, v. 2, n.2, p. 221-244, jul./dez. 2004 
Unidas, de 30 de agosto de 2002, no debate sobre a necessidade de se reforçar a prevenção contra o terrorismo, foi exposto que este somente pode ser erradicado através da participação de todos os membros da comunidade internacional em um esforço compreendido globalmente, sob os auspícios das Nações Unidas, uma vez que a luta contra tais atos ilegais se tornou uma questão de grande prioridade desde os ataques desferidos contra os Estados Unidos em 11 de setembro de 2001. Afirmou-se também que o fenômeno do terrorismo não pode estar associado a nenhuma religião, nacionalidade ou etnia. ${ }^{56}$ Para o seu combate é necessário que haja o posicionamento de toda a comunidade internacional de forma a não ser aceita qualquer justificativa para a retirada da vida de civis.

O fato é que, certamente, o terrorismo internacional será um tema relevante da nova agenda internacional. Existe uma questão bastante importante para a comunidade internacional que seria a de que, se por um lado existe a possibilidade de um alastramento do conflito entre os demais países, por outro não se pode permitir que em nome da luta contra o terrorismo o direito venha a ser descartado e ações extremas e violentas encontrem respaldo e justificativa. ${ }^{57}$ Algo que não pode ser refutado é que o combate ao terrorismo tem de ser feito sob o espírito das regras democráticas internacionais, tendo-se uma preocupação em não promover uma limitação aos direitos individuais e, principalmente, afirmando-se respeito aos Direitos Humanos. Não se pode, em nome de derrotar essa ameaça, arriscar as liberdades já conquistadas. A ação contra o terrorismo não pode justificar a repressão ilegal. Ou seja, tem-se que pensar em um combate ao terrorismo sob os preceitos do Direito Internacional e de acordo com uma ação coordenada de toda a comunidade internacional. Pois, caso, em nome da luta contra o terrorismo, fossem restringidas liberdades, que são direitos fundamentais e se se renunciasse aos Direitos Humanos, esse combate perderia muito da sua legitimidade.

\footnotetext{
${ }^{56}$ Disponível em: 〈www.unodc.org/unodc/en/terrorism.html〉. Acesso em: 23 de setembro de 2003.

${ }^{57}$ BRANT, Leonardo Nemer Caldeira. Introdução In:Terrorismo e Direito op. cit. p. 4-5
}

Universitas - Relações Int., Brasília, v. 2, n.2, p. 221-244, jul./dez. 2004 


\section{REFERÊNCIAS BIBLIOGRÁFICAS}

BAYLIS, John; SMITH, Steve. The Globalization of World Politics: an introduction to international relations. Second Edition New York: OXFORD, 2001.

BOBBIO, Norberto; MATTEUCCI, Nicola; PASQUINO, Gianfranco. Dicionário de Política. Tradução de Carmen C. Varriale, Gaetano Lo Mônaco, João Ferreira, Luís Guerreiro Pinto Cacais e Renzo Diniz. 11 ${ }^{\text {a }}$ ed. Brasília: Editora Universidade de Brasília, 1998.

CARR, Caleb. Tradução de Mauro Silva. A assustadora história do terrorismo. São Paulo: Ediouro, 2002.

CARVALHO, José Reinaldo; CARVALHO, Lejeune Mato Grosso de. Conflitos Internacionais num mundo globalizado: Palestina, Iraque, Venezuela e a Hegemonia Americana. 2 ed. São Paulo: Editora Alfa - Omega, 2003.

CHOMSKY, Noam. 11 de Setembro. Tradução de Luiz Antonio Aguiar. 4 ${ }^{\mathrm{a}}$ ed. Rio de Janeiro: Bertrand Brasil, 2002.

CLUTTERBUCK, Richard. Guerrilheiros e Terroristas. Tradução de Virgínia Bombeta. Rio de Janeiro: Biblioteca do Exército Editora, 1977.

HUNTINGTON, Samuel. O Choque das Civilizações. Tradução de M. H. C. Cortês. Rio de Janeiro: Objetiva, 1997.

KENEDDY, Paul, et al. A Era do Terror. Organizadores: Strobe Talbott e Nayan Chanda. Tradução de Cristiana Serra. Rio de Janeiro: Editora CAMPUS, 2002.

KEOHANE, Robert O.; NYE, Joseph S. Power and Interdependence. Third edition. London: Longman, 2001.

LESSER, Ian O.; HOFFMAN, Bruce; ARQUILLA, John; RONFELDT, David; ZANINI, Michele. Countering the new terrorism. Washington D.C.: RAND, 1999.

NETO, Francisco Paulo de Melo. Marketing do terror. São Paulo: Contexto, 2002.

NYE, Joseph S. Junior. Compreender os conflitos internacionais: Uma Introdução à Teoria e à História. Tradução de Tiago Araújo. $3^{\mathrm{a}}$ ed. São Paulo: Gradiva, 2002.

Universitas - Relações Int., Brasília, v. 2, n.2, p. 221-244, jul./dez. 2004 
SENNA, Adrienne Giannette Nelson de, et al. Terrorismo e Direito: os impactos do terrorismo na comunidade internacional e no Brasil. Coordenador, Leonardo Nemer Caldeira Brant. Rio de Janeiro: Forense, 2003.

SUTTI, Paulo; RICARDO, Silvia. As Diversas Faces do Terrorismo. São Paulo: editora HABRA, 2003.

VIOTTI, Paul R.; KAUPPI, Mark V. International Relations Theory: Realism, Pluralism, Globalism and Beyond. Third Edition Allyn \& Bacon, 1999.

\section{REVISTAS}

Política Externa Vol. $11 \mathrm{n}^{\mathrm{o}}$ 3. São Paulo. Dezembro - Janeiro Fevereiro 2002/ 2003.

O Império Vulnerável. Revista Veja. Editora Abril. Edição 1718. ano 34 no 37 Edição Especial. 19 de setembro de 2001.

\section{ENDEREÇOS ELETRÔNICOS}

Organização das Nações Unidas:

www.unodc.org/unodc/en/terrorism.html

Polícia Internacional Criminal (INTERPOL): www.interpol.int 